\title{
Addressing Water Quality Issues in Rural Cameroon with Household Biosand Filters
}

\author{
Laine Klopfenstein \\ Junior, Department of Engineering \\ Hope College \\ Holland, MI 49423 \\ laine.klopfenstein@hope.edu \\ Laura Petrasky \\ Senior, Department of Engineering \\ Hope College \\ Holland, MI 49423 \\ laura.petrasky@hope.edu \\ Valerie Winton \\ Senior, Department of Chemistry \\ Hope College \\ Holland, MI 49423 \\ valerie.winton@hope.edu \\ Jeff Brown \\ Asst. Professor, Department of Engineering \\ Hope College \\ Holland, MI 49423 \\ jbrown@hope.edu
}

Abstract - This paper describes an ongoing collaboration between the Hope College student chapter of Engineers Without Borders - USA and the rural community of Nkuv in the Northwest Province of Cameroon related to improving drinking water quality using Manz biosand filters. The collaboration began in 2006 and focused on developing a communitybased construction and distribution model for household water treatment units. Results from microbiology testing of the constructed filters indicate that this water treatment method is effective for improving water quality in rural areas. The results also highlight the need for ongoing assessment and adapting community education programs to provide necessary training for filter construction and maintenance. The critical finding from this study is that transferring this technology in rural settings in developing countries may require years of iterative intervention and site specific adjustments to the construction and distribution model.

Index Terms - Biosand filters, household water treatment, community-based water projects

\section{INTRODUCTION}

According to the World Health Organization (WHO), more than one in six of the world's population lacks access to the amount of safe drinking water necessary to fulfill their basic needs. This is primarily due to an insufficient local supply of clean water. Water supplies in many areas, both rural and urban, are heavily polluted with biologically toxic impurities. This 
contamination leads to waterborne illnesses and is a leading cause of death, especially in children under the age of five. Responses to this global issue have often involved collaboration between external organizations and locals to implement solutions. In the effort to alleviate biological contamination, slow sand filtration units are often implemented. In 2005 a project was proposed to Engineers Without Borders-USA (EWB) regarding a potential water project in Cameroon. Upon acceptance of the project, a partnership was established between the Hope College student chapter of EWB and a local organization known as Life and Water Development GroupCameroon (LWDGC) and the small rural community of Nkuv, Cameroon.

\section{The Community of Nkuv}

Nkuv, Cameroon, is a small farming community located in the northwest region of Cameroon, situated approximately 10 miles away from Kumbo, which is the largest neighboring regional city. The journey from Kumbo to Nkuv entails either a four hour trek by foot, or a two hour truck ride traversing a road that is very poorly maintained due to severely limited infrastructure. Nkuv has a population of about 700 inhabitants, which are split geographically among four village quarters: Ndzen Dzui, Roovisem, Rosang, and Tankuv. The majority of the population, approximately 75\%, resides within Rosang and Tankuv. The village is situated in a valley through which several streams of varying size and turbidity flow, with another ethnic group living in the surrounding hills. This neighboring community herds cattle in the hills, leading to downstream fecal contamination, primarily after rainfall. The combination of fecal contamination and other human activity induces extremely high E. coli levels in the river waters, therefore rendering them unsafe drinking water sources. Rivers in Nkuv have been found to contain up to 1000 coliforms per $100 \mathrm{~mL}$, which is 100 times higher than the generally accepted standard of 10 coliforms per $100 \mathrm{~mL}$. With no alternate water sources, the widespread consumption of this contaminated drinking water highly compromises community health.
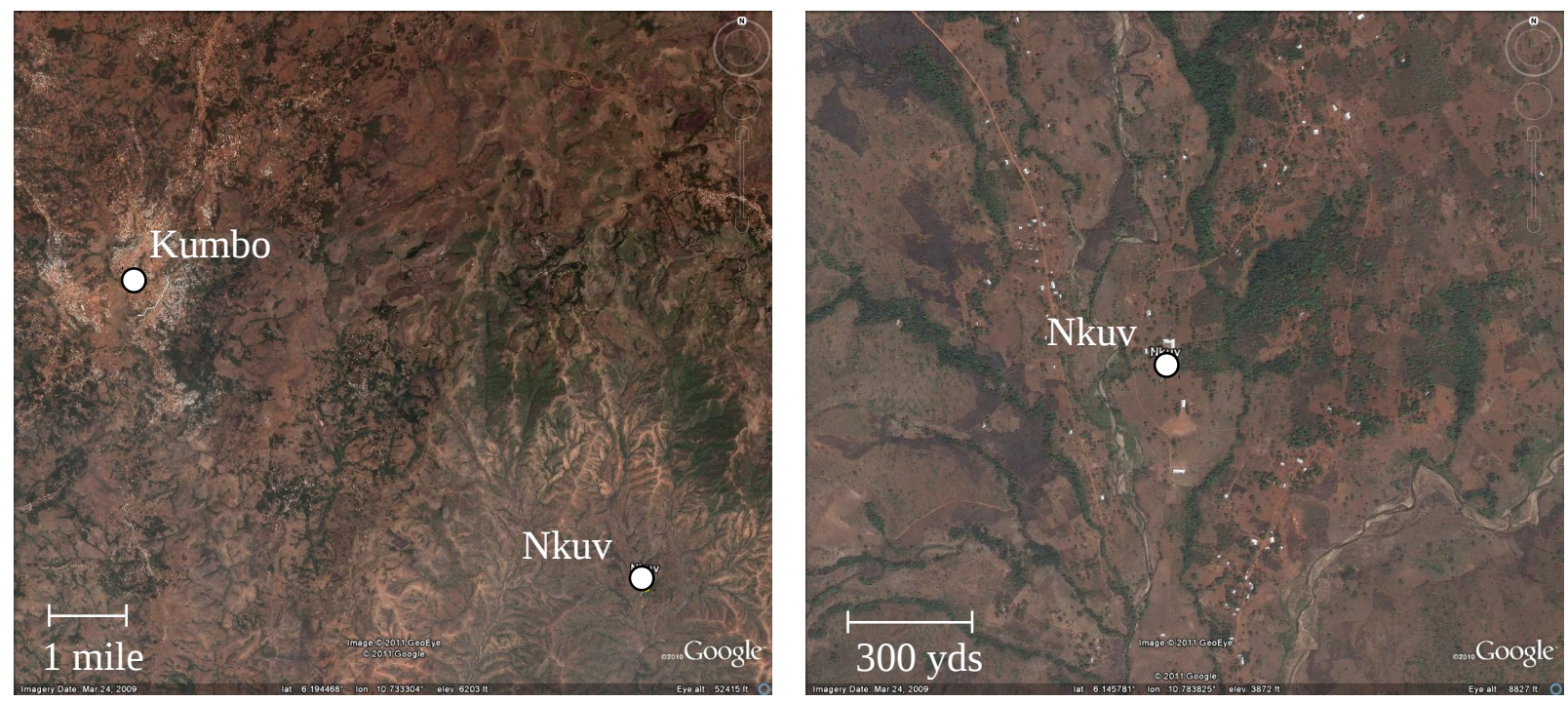

FIGURE 1

LOCATION MAP FOR NKUV, NORTHWEST PROVINCE, CAMEROON 


\section{Life and Water Development Group - Cameroon}

The Life and Water Development Group - Cameroon (LWDGC) is a nongovernmental organization (NGO) that was founded by Peter Njodzeka, a Cameroonian and native of Nkuv. The purpose of this organization is to improve the quality of life in local communities, with a focus on rural areas. Toward this end, Njodzeka applied to several international aid groups, including Engineers Without Borders-USA (EWB-USA), requesting support for a project to improve the water quality in Nkuv. The project was accepted by EWB-USA, and subsequently assigned to the EWB-Hope chapter. Other projects of LWDGC include the implementation of Manz biosand filters in elementary schools in the Kumbo area. LWDGC also receives funding from Thirst Relief International, which supports filter projects throughout the region.

\section{EWB-Hope}

EWB-Hope is a student chapter of Engineers Without Borders-USA and was founded in 2005 at Hope College in Holland, Michigan. The group was chiefly interested in finding a project that would allow for integration of nursing and engineering. After applying for several projects throughout the world, the chapter was paired with LWDGC and the proposed water project in Nkuv, Cameroon. In March 2006, EWB-Hope conducted its first assessment trip and had initial meetings with Peter Njodzeka as well as the community of Nkuv. A major focus of the group was to use an interdisciplinary approach - including engineering, nursing, and education - to not only address the water quality issue, but also to increase health and hygiene awareness in the community and ensure sustainability of the project.

\section{A Question}

While the goal of this project was to work with the village of Nkuv to develop a sustainable and realistic solution to the issues of water quality, there was also a larger consideration. A crucial and fundamental question dealt with the role of the EWB chapter in household water treatment, and the appropriate extent of involvement in the implementation phase. Should EWB-Hope be responsible for the construction and distribution of the filters, or should the group only assume responsibility for the training and education of Nkuv community members, who would then carry out the project implementation themselves? Another important consideration for any type of community based training is determining the proper balance of theoretical and practical content. Answering these questions at an early phase was necessary to make fundamental decisions about how much time would be spent in the community and how many team members from Hope College would be needed to execute the chosen strategy. Other fundamental questions related to which materials would be used to construct the filter bodies (plastic vs. concrete) and where the media for the filters be obtained (imported or locally).

\section{The Project}

In May 2006, a group traveled to Nkuv in order to assess different options for providing the village with a safe drinking water source. The community expressed a desire for drilling shallow wells, a solution that some of their neighboring communities had used. There were several factors, however, that made this solution unattractive. Multiple attempts were made over a two week period by the community and the EWB-Hope team to drill shallow wells using hand auger equipment. These attempts were not successful due to the hydrogeological condition of the area. The possibility of drilling deeper wells was also not practical because of the extremely poor road 
conditions between Nkuv and Kumbo. Finally, there was never a history of centralized water collection in Nkuv and residents had access to apparently clean water throughout the year via surface water streams. The relatively low population density meant that if wells were found to be practical a large number of them would be needed to ensure access by the entire community. Though the community was somewhat reluctant to abandon the concept of shallow wells, the decision was reached through consensus and everyone was satisfied that every reasonable effort had been made to explore this option. Fortunately, the May 2006 team was also prepared to introduce an alternative that included household water treatment using Manz biosand filters.

\section{Biosand Filters}

The biosand filter employs a gravity-driven slow sand filtration process for the purpose of water decontamination. Two classes of biological pollutants predominate in the Nkuv river water: parasites and bacteria. The sand itself mechanically removes all parasites from the water, provided that the particle size is of the correct scale. For the bacteria, a portion is removed mechanically by the sand, and an aqueous biological layer overlaying the sand effectively eliminates the majority of remaining bacteria. The resulting water displays $60-99 \%$ bacterial removal, with the exact degree of removal dependent on the quality of filter construction and maintenance. The Manz filter design was chosen because nearly all materials required for its construction - excluding cement and a small amount of PVC pipe - are locally available in Nkuv. This was an important consideration since transporting materials to the village is a significant challenge due to its remote location and poor accessibility. The rock, sand and water needed to build the Manz filter could all be obtained in Nkuv. The filter design also requires a set of reusable metal forms, which were delivered in sections via truck from Kumbo to the village when required, and assembled on site.

Instead of designing a single large community filter, a system involving individual household filters was employed in order to make filtered water more immediately available to each household. At the time, there was no centralized water distribution system in Nkuv, which is a key requirement for a community scale treatment facility. In addition, this organizational structure provided each family with a greater sense of ownership and responsibility regarding their filter.

\section{Filter Construction}

The complete construction time for a household filter typically lasts a period of several days. Casting the body requires hand-mixing the concrete, which then must cure for about a day in the assembled metal form. Once out of the mold, a few days must pass until the filter body is ready for media installation. In addition, the sand and pebbles installed within the filter require intensive preparation. The sand is initially harvested from local streams, thoroughly washed and dried to remove fine sediment, and then sifted through multiple screens of various sizes in order to achieve the proper particle size for each layer of the media. The materials for the screens were purchased in a nearby city, and they were constructed onsite. The correct particle size must be ensured for a filter to function with an optimal flow rate and bacterial removal. It took a maximum of several days to produce the correct quality and quantity of sand, depending on the initial quality of the raw material found in the streams. Once the components were collected, a filter was assembled and started in about 30 minutes. The filters were built at homes, as opposed to at a central location, and in most cases the construction materials were gathered by the individual families themselves. This participation was encouraged with the purpose of promoting 
a sense of ownership by the families instead of having the community members feel as if the filters belonged to EWB-Hope or LWDGC. If the filter is regularly used, it will require several weeks before the filter is functioning at maximum performance and achieving a high bacterial percent removal. This period of time is needed for the Schmutzdecke to grow. The Schmutzdecke is a biological layer that preys on the E. coli and other harmful bacteria found in contaminated drinking water. This layer grows in the top few inches of the final sand layer.

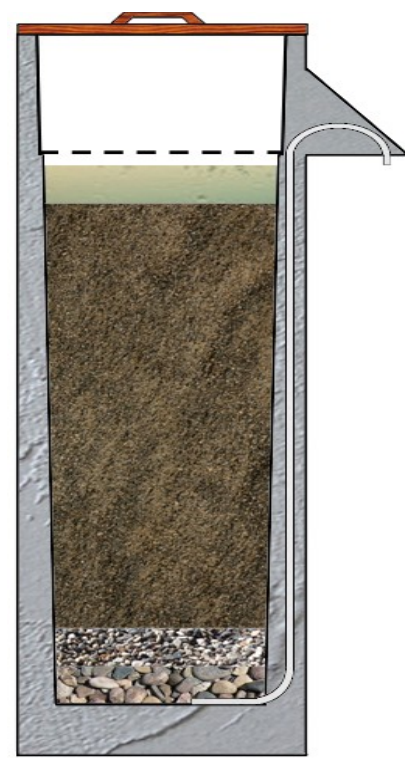

FIGURE 1

BIOSAND FILTER CROSS-SECTION

A functioning filter has three layers of sand and gravel. The fine sand $(\leq 0.7 \mathrm{~mm})$ comprises the largest section of the filter and has a depth of $543 \mathrm{~mm}$. Underlying the fine sand is a layer of small separating gravel $(0.7 \mathrm{~mm}-6 \mathrm{~mm})$ followed by a base layer of larger drainage gravel $(6 \mathrm{~mm}$ $-12 \mathrm{~mm}$ ) both of which have a depth of about $50 \mathrm{~mm}$. These values are in accordance with recommendations by the Center for Affordable Water and Sanitation Technologies (CAWST). Furthermore, the filter is constructed so as to maintain two inches of standing water at the top of the sand, which promotes biolayer growth. The depth was estimated with a ruler, and, at installation, fine sand was added or subtracted until the correct standing water depth was obtained. Other key components of a filter include a lid, which keeps the filter interior clean, and a diffuser plate which allows buckets of water to be poured into the filter without disturbing the biolayer or top sand layer, either of which would decrease the efficiency of the filter. For the construction of the filter body, concrete mixes of 1-1-1 (sand to cement to gravel) or ideally 1-1$1-2$ (which is one part gravel $(12 \mathrm{~mm}$ ) to one part sand $(3 \mathrm{~mm})$ to one part cement, and two parts fine sand $(.7 \mathrm{~mm})$ ). Once the production of filters had been taught to the community, the second mix is used, which decreases the amount of cement needed, and incorporates the special sized sand and gravel produced by media preparation/sifting. 


\section{Sustainability-Filter Technicians}

In order to ensure that filter construction would continue after the departure of EWB-Hope, a group of local community members were trained in this area. Training included instruction on filter body construction, correct media preparation and installation, and necessary maintenance. This training was done through demonstrations, and a manual was developed for future training. Contact was maintained with LWDGC throughout the year via email, and EWB-Hope has used several follow-up trips to address concerns that arise. The training received by LWDGC, along with access to construction manuals, has allowed for the continuation of the project beyond Nkuv and the involvement of EWB-Hope. Although a group of local technicians underwent training, many of them did not have the necessary free time to devote to filter construction. Members of LWDGC were also trained to continue filter construction throughout the region.

While the training of the technicians allowed filters to be built without direct support from EWB-Hope, several problems arose. Although this system was designed to ensure the possibility of additional filter construction, the funds and motivation necessary to enact this were lacking, especially since the households were not charged for filters under the model being used to distribute the filters. However, this problem was alleviated when LWDGC received a grant from Thirst Relief International to build more filters. The funds provided payment for the filter technicians, and the pressure to produce additional filters elicited the quick construction of many filter bodies. However, this left the technicians with insufficient time to correctly prepare the media for so many filters in a short period of time. As a result, many filters were filled with sand of an incorrect particle size, thereby significantly hindering their ability to remove bacteria. This does not mean that the filters were not functioning at all. Rather, those that were being tested would have a removal efficiency rate closer to $75 \%$, as opposed to a more optimal rate between $90 \%$ and $95 \%$. In the future, this issue would ideally be corrected by training more community members in media production, which would decrease the amount of work allotted to the technicians and also increase the sense of ownership by the families. Another problem that was encountered was that most of the trained technicians employed by LWDGC left Nkuv after filter construction in the village was complete. Although the purpose of this was to extend filter construction to other regions, it left Nkuv lacking in permanent community members that were well-versed in filter construction and maintenance. While there were several community members who fully supported the project, they lacked the resources to maintain all of the filters. Family ownership became an important aspect for the ongoing care of the filters.

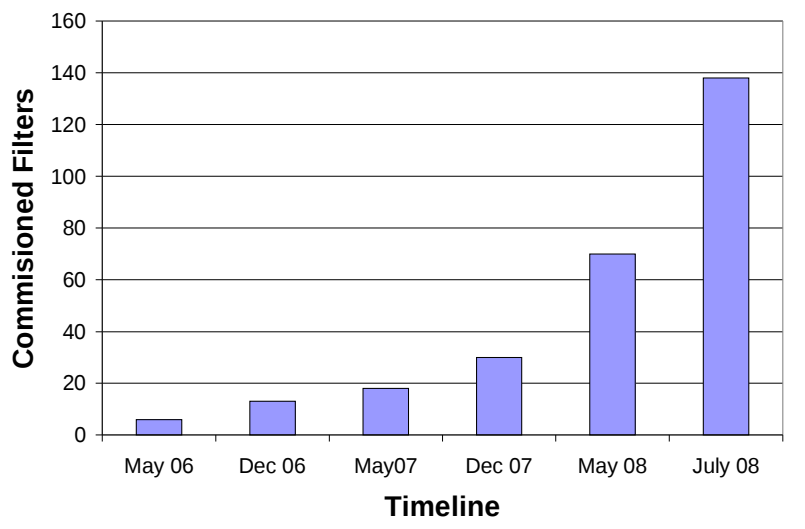

FIGURE 2

TIMELINE FOR FILTER PRODUCTION IN NKUV, CAMEROON. 
Although the use of filter technicians was generally effective, there remained several areas in which some adjustments were beneficial. One improvement was the shift from technician-prepared media to family-prepared media. This delegation of work lends itself to enhanced family involvement in filter preparation as well as greater personal investment in the project, especially for mothers in the community who were taught about filter care through workshops held for their women's group. Many of the community mothers were also invested in helping their families become healthier and were willing to learn what materials were necessary for filter production. Furthermore, the technicians were freed to have more time for filter body construction. Another source of inefficiency was the absence of technicians residing locally. As the project continued over the course of two years and several visits to the community, more of the community members were trained so that the knowledge of the filters was not isolated to the technicians.

\section{Sustainability-Community Involvement}

An integral component of project implementation was garnering community support and involvement. While the benefit of cleaner water was acknowledged, community training toward proper filter use presented a challenge. This was primarily due to challenges in communication and a general lack of higher education, which propagated difficulties in grasping scientific principles. While this had no effect on the ability of community to produce or use filters, it did result in some difficulty in explaining how the filters worked. Once a filter was installed in a home, it was intended that the family would be trained in basic filter maintenance; however, due to the transient nature of the community, this knowledge was not consistently transferred to new owners. LWDGC, of which members were also trained, has projects throughout Cameroon, and the amount of time they spend in Nkuv varies. This also causes inconsistency in the transfer of knowledge regarding the filters within the community. In order to address this issue, community workshops were held to increase awareness and address individual problems. One significant issue was filter ownership; while some members of the community owned filters but were not using them, others had the desire for a filter but no access to a filter. After community discussions in May 2009 and 2010, it was decided to form a group of men responsible for moving assembled yet unused filters to homes where they were wanted. In addition, the health and education members of the EWB-Hope team developed lessons that taught basic filter maintenance and safe water handling techniques. The lessons were taught to various women's groups, and were compiled into booklets that women who completed the course would receive. The women were also taught to teach the lessons to others so that the knowledge could continue to spread. Similar lessons were taught in the schools. This proved to be an integral component of introducing the filters in Nkuv. As the awareness of the role of water in health problems as well as the value of water filtration increased, the presence of filters in the community strengthened.

Because the filters require that the water is run through them at a moderately slow rate, the time necessary to obtain clean drinking water is increased. However, this proved to be a minor issue, especially as the filters became more commonly used within the community. It was important to endow the first biosand filters to people who would not only use them consistently, but who were also leaders in the community. The decision of who to give filters to was made jointly between LWDGC, EWB-Hope, and community members. As these families observed the benefits of the filters, such as decreased disease in their children, they promoted the filters to their neighbors which increased the demand for filters. In general, there was widespread and 
strong community support for the filters, and many villagers grew very excited and enthusiastic about the filters and their health benefits.

\section{Data Collection}

The goal of EWB-Hope was not only to implement biosand filter use and to improve community knowledge regarding the filters, but also to identify a method of evaluating their functionality and determining their efficiency. Microbiological testing was conducted to quantitatively evaluate the bacterial removal rates of the filters, in conjunction with asking survey questions of filter users to evaluate community perception of the filters. Questions that were addressed included: do the filters satisfy the family's needs, do the families have the knowledge to maintain the filters, are the filters working, are there problems with the production of the filters, and was the training of the filter technicians adequate? In order to probe these questions, household surveys were conducted throughout Nkuv. While conducting these surveys, water samples from the filters were collected in order for subsequent microbiological analysis for $E$. coli content.

\section{Microbiology}

Quantitative microbiological analysis was performed in an on-site testing lab. The remote location of Nkuv and the lack of any larger facilities in nearby towns capable of performing membrane filtration tests for E. coli mandated this decision. When the program began in 2006, the student team used an Oxfam-Delagua water testing kit to perform membrane filtration analysis. The Oxfam kit utilizes a membrane lauryl sulfate broth to enhance bacteria growth and a battery powered incubator to maintain the temperature of the samples at $44^{\circ} \mathrm{C}$ for 18 hours. This kit was very useful in the early stages of the program when the testing goals were limited to determining the raw water quality and evaluating the performance of a small number of filters (less than 5 over a one week period).

Once the program expanded and testing goals increased to approximately 25 filters in a two week period, the Oxfam-Delagua posed serious limitations. First and foremost, the incubator could only hold 16 Petri dishes per incubation cycle. The testing program that was developed for each filter in Nkuv required nine Petri Dishes per filter (three for raw water, three for filtered water with 12 hour residence time, three for filtered water with no residence time). Several options were investigated to increase the capacity of the water testing program such that membrane filtration results could be obtained for up to five filters (40 Petri dishes) in a 24 hour period. The general procedure for obtaining and processing samples is described below.

1. Pre-sampling consultation. A member of the biosand filter team and a translator would visit the household containing the filter to be evaluated in the late afternoon/early evening on the day before the sampling was to occur. The family was instructed to run one bucket of water through the filter before nightfall and then to wait until the filter team revisited the household the following morning before any additional water was placed in the filter. This established a minimum residence time of approximately 12 hours before the sampling occurred.

2. Source water evaluation and sampling. The filter team arrived at the household in the early morning hours (around $6 \mathrm{am}$ ) and accompanied the family to retrieve water. The location in the stream where the source water was collected was noted as well as the total time required to retrieve the water. Before the bucket of water was placed in the filter, a 
$300 \mathrm{~mL}$ sample of the raw water was collected in a sterile Whirl-Pak polyethylene sampling bag.

3. Filtered water sampling. Before the water was placed in the filter, a second sterile bag was made ready and held at the filter outlet. A second team member would empty the bucket into the filter reservoir and initiate flow from the filter. Once $300 \mathrm{~mL}$ of filtered water was obtained, the bag was sealed and labeled "first-out." This sample represents water with an approximate residence time of 12 hours. A third sterile bag was then prepared and $300 \mathrm{~mL}$ of filtered water was collected after $50 \%$ of the treatment volume had passed through the filter. This sample was labeled " $1 / 2$ through" to indicate water that had passed through the filter but did not have any residence time.

4. Microbiology Analysis. Microbiological testing involved the use of a Millipore membrane filtration apparatus and a chicken-egg incubator. All water quality testing materials were brought from the U.S. After carefully opening the sample containers, a specific volume of sample was drawn through a filter paper using the Millipore apparatus. This trapped any bacteria or other particles that were in the water on the surface of the paper. For the raw, first-out, and 1/2 through water samples, $10 \mathrm{~mL}, 50$ $\mathrm{mL}$, and $20 \mathrm{~mL}$ were used, respectively. The paper was then transferred into a labeled petri dish loaded with $1.8 \mathrm{~mL}$ of Coliscan MF broth. This process was repeated three times for each water sample to obtain more accurate results and ensure reproducibility. All equipment was flame-sterilized between each water sample.

5. Incubation. Petri dish samples were placed in the incubator, which was set to $37^{\circ} \mathrm{C}$, the average human body temperature, to most accurately simulate the thermal conditions in which bacteria would grow after water consumption. Samples were left to develop overnight, typically for a period of about 18 hours, after which they were removed from the incubator and analyzed. Sample analysis involved the counting of E. coli colonies, as shown by the indicator-containing broth as a blue dot on the paper. This quantity was then mathematically adjusted to represent the number of coliforms per $100 \mathrm{~mL}$ to enable consistent comparison among samples.

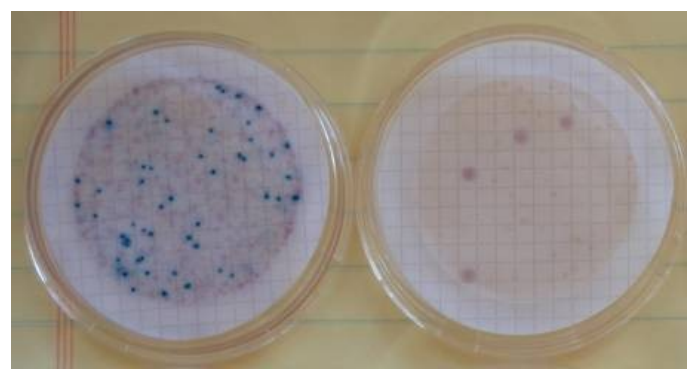

FIGURE 3

EXAMPLE OF PETRI DISH SAMPLES: RAW SAMPLE, 10ML (LEFT), FIRST-OUT, 50ML (RIGHT)

\section{RESULTS}

\section{Quantitative}

The microbiology testing procedure described above provided a framework for determining if the filters were functioning correctly and removing the biological contaminants effectively. The 
microbiology testing took place on two assessment trips conducted by EWB-Hope, in May 2008 and May 2009.

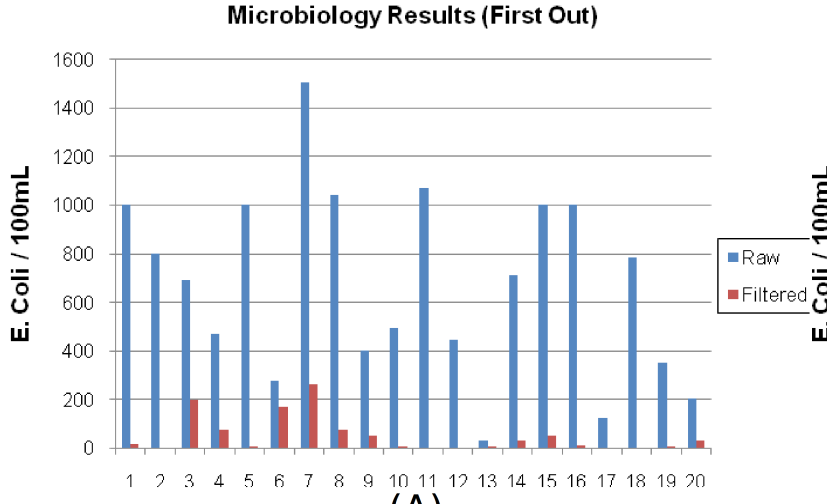

(A)

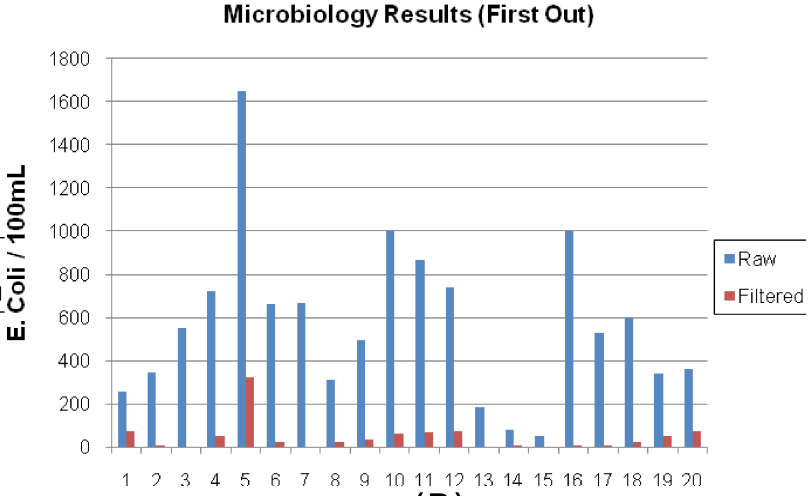

(B)

FIGURE 4

MICROBIOLOGY RESULTS FOR FIRST OUT FILTERED WATER. (A) MAY 2008, AVERAGE REMOVAL = 90.2\%, (B) MAY 2009, AVERAGE REMOVAL = 92.4\%. FIRST OUT INDICATES FILTERED WATER WITH 12 HOUR RESIDENCE TIME

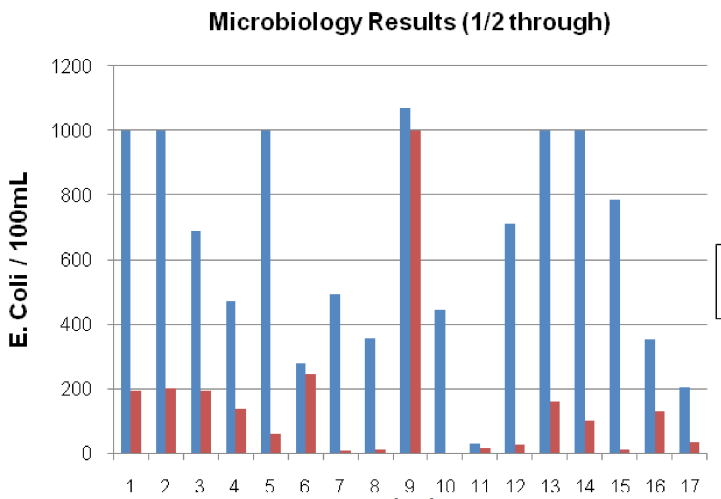

(A)

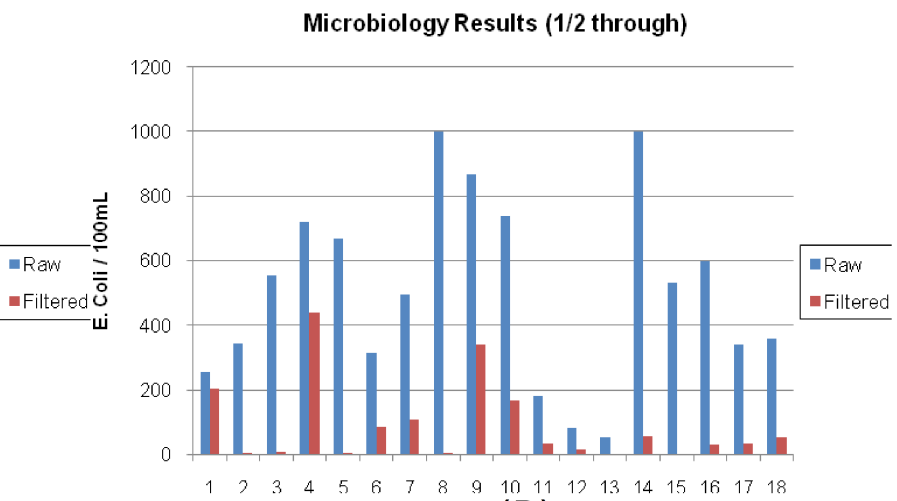

(B)

\section{FIGURE 5}

MICROBIOLOGY RESULTS FOR $1 \frac{1}{2}$ THROUGH FILTERED WATER. (A) MAY 2008, AVERAGE REMOVAL $=70 \%$, (B) MAY 2009, AVERAGE REMOVAL $=82 \% .1 / 2$ THROUGH INDICATES FILTERED WATER WITH NO RESIDENCE TIME

Figure 4 shows the results of the first water out of the filter, which has the maximum amount of residence time (around 12 hours) in the filter." Since the water is in the filter for a longer time, the biolayer can more efficiently remove the contaminants. These results show that the filters are working well at removing the E. coli, and also that the filters are being cared for, since the average removal improved after a year.

Figure 5 shows microbiological results for water which was collected when half of the added water volume had passed through the filter. This implies that the residence time is greatly decreased, and is reinforced by the drop in average filter efficiency. Results confirm the 
importance in conducting microbiology testing on water collected at multiple points during the filtration process, since the amount of bacteria removed is much less for $1 / 2$ through than for first out. These data also indicate that since bacterial removal decreases with diminished residence time, it is important to take additional disinfection measures (such as chlorination) in order to render the filtered water entirely bacteria-free.

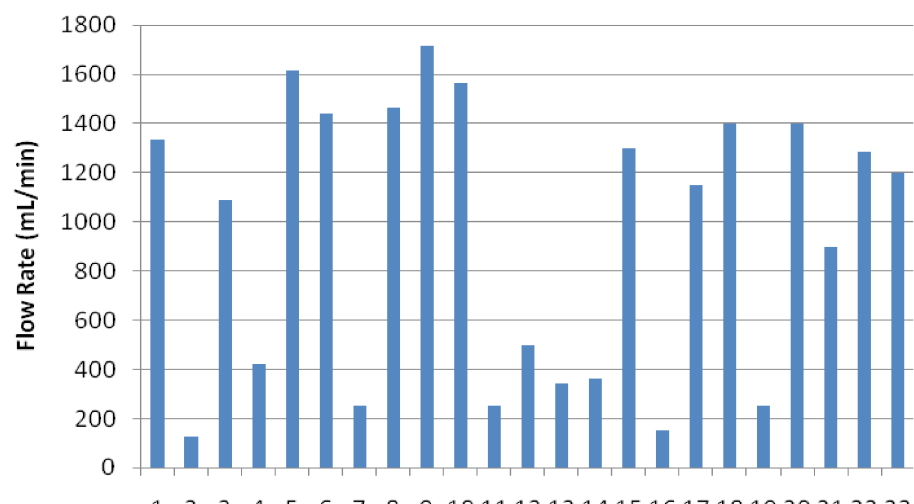

$\begin{array}{llllllllllll}1 & 2 & 3 & 4 & 5 & 6 & 7 & 8 & 9 & 1011 & 1213141516171819202122 & 23\end{array}$

(A) 2008

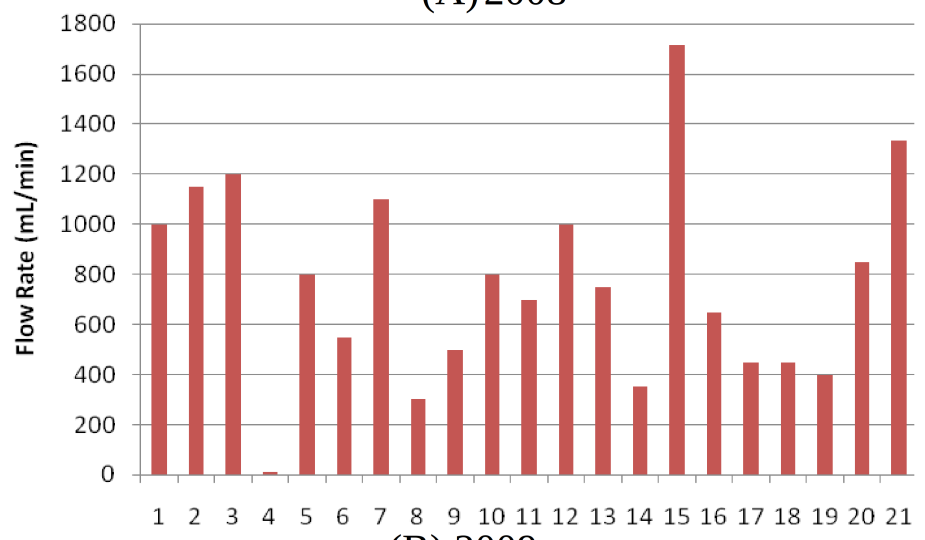

(B) 2009

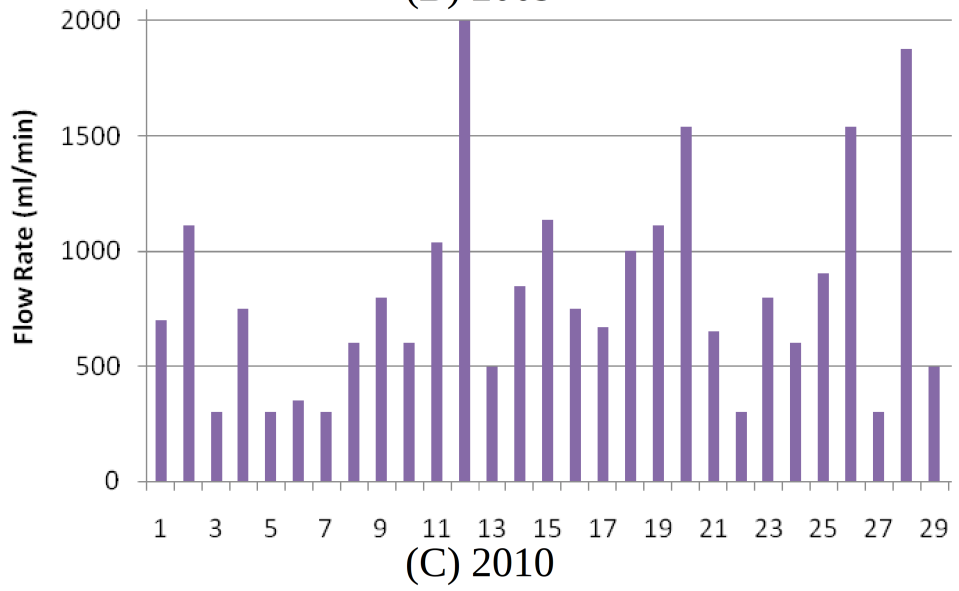

FIGURE 6

MEASURED FLOW RATES FOR FILTERS SURVEYED 
Another interesting result was the measurement of flow rate. Since the residence time directly affects the amount of contaminant removal, it logically follows that filter effectiveness will increase as flow rate decreases. However, a moderate flow rate is ideal, since families will cease filter use if the flow rate is so slow as to be impractical for daily use. The flow rate is directly correlated to the particle size of sand within the filter. According to CAWST, a leader in the development of the Manz Biosand filter technology, the flow rate should be $1 \mathrm{~L} / \mathrm{min}$ or slower at the time of installation (the flow rate is measured when the reservoir is full). The actual flow rate varies depending on the specific version of the filter body used and the recommended flow rate for the most recent version of the filter is $600 \mathrm{~mL} / \mathrm{min}$. Many of the tested filters had flow rates that were higher than this cutoff (Figure 6), indicating that they had been constructed using sand of an incorrect particle size. This observation can be traced back to the period in which many filters were constructed in a short period of time, leaving the filter technicians insufficient time to thoroughly prepare and sift the media. This problem has hopefully been corrected through more extensive technician training and education, and through the delegation of tasks required to build filters to more community members and households.

Through partnering with the education and nursing teams, data on the health effects of the filters were also gathered. Surveys of the overall health of all children under the age of 5 were taken. Of these families, $81.1 \%$ in 2008 who filtered water reported no diarrhea or blood in stool, which is close to $20 \%$ more than those consuming unfiltered water.

\section{Qualitative}

In addition to the microbiology testing, the surveys also analyzed the qualitative data to observe how the filters were working in the community.

TABLE 1

SURVEY RESULTS

\begin{tabular}{|c|c|c|c|c|}
\hline Year & $\begin{array}{c}\text { Number of Families } \\
\text { Surveyed }\end{array}$ & $\begin{array}{c}\text { Filters with a } \\
\text { Clean Interior (\%) }\end{array}$ & $\begin{array}{c}\text { Families Indicating } \\
\text { Benefit from Filter (\%) }\end{array}$ & $\begin{array}{c}\text { Filters with Correct Standing } \\
\text { Water Depth (2" } \pm 0.5 ")(\%)\end{array}$ \\
\hline 2008 & 26 & 80.8 & 83.3 & 72.0 \\
2009 & 23 & 87.0 & 95.2 & 59.1 \\
2010 & 40 & 92.3 & 100.0 & 52.9 \\
\hline
\end{tabular}

As evident in Table 1, the level of satisfaction with the filters in the community increased as the project continued. Families that indicated benefit usually pointed to better family health, and also in most cases acknowledged that the water looked cleaner. Families in Nkuv also began to take better overall care of their filters with respect to cleaning them, but the number of filters with the correct standing water depth decreased. This is most likely due to the fact that if they are not installed correctly the first time, they were rarely fixed. Many of the filters had an incorrect water depth by about 1". This finding points to the need for an ongoing presence within the village of technical expertise to perform minor repairs on filters that need attention, either due to improper construction or for ongoing use. While the model is in continual development, it is still far from perfect.

In 2009, a section of the survey asked if filter users knew how to clean the media (internal) part of the filters. It was discovered that just over $50 \%$ did. Due to this fact, filter cleaning 
lessons were taught during community workshops as well as during home visits during the rest of the 2009 trip, which resulted in an increase in the number of families who knew how to clean the filters when asked in 2010. The education continued in the May 2010 trip. The results of this change can be seen in Table 2 .

TABLE 2

PERCENTAGE OF FAMILIES WHO KNOW HOW TO CLEAN FILTER

\begin{tabular}{|c|c|c|}
\hline Year & $\begin{array}{c}\text { Number of Families } \\
\text { Surveyed }\end{array}$ & $\begin{array}{c}\text { Know How to Clean } \\
\text { Filter (\%) }\end{array}$ \\
\hline 2009 & 23 & 54.2 \\
2010 & 40 & 77.5 \\
\hline
\end{tabular}

This method of household surveying was found to be effective for detecting problems with the method of introducing the filters to the community. It also appears to be successful at determining new problems within the community as they arise. For example, recent surveys showed a decrease in the percentage of filters with lids.

TABLE 3

PERCENTAGE OF FILTERS WITH LIDS IN PLACE

\begin{tabular}{|c|c|c|}
\hline Year & Number of Families Surveyed & Lid in Place (\%) \\
\hline 2008 & 26 & 80.0 \\
2009 & 23 & 87.0 \\
2010 & 40 & 80.0 \\
\hline
\end{tabular}

Upon conferring with community members, it was discovered that many no longer had lids due to rotting of previously used lids, and a lack of motivation or feeling of urgency to replace them. This discovery points to the need for further community education on filter maintenance and on the importance of each component (including lids) of the filters.

\section{CONCLUSIONS}

Results detailed within this document indicate the sustainability and effectiveness of this biosand filter project in the effort to provide the village of Nkuv with cleaner drinking water. The community has begun to take ownership of the filters, and has recognized a marked improvement in the overall health of community members. While the partnership with the village is far from complete, the relationships formed with the community and the educational advancements have functioned as integral parts of this project. Reassessment of filter efficiency and function provides valuable insight into problems that have arisen during earlier project implementation, as does ongoing communication with LWDGC and the community.

In regards to the question posed at the beginning of this paper, namely defining the appropriate role of an EWB chapter in household water treatment, some interesting conclusions can be drawn. The data clearly indicate that the filters are often constructed with more care and attention to details and specifications when built by EWB members. Issues in the media 
preparation and in incorrect standing water level imply that the method of training only filter technicians for filter construction may not be as effective as had been hoped. However, the overall number of families in the village with filters is considerably greater when locally trained members of the community are responsible for installing the filters. Improved education of filter technicians and increased community involvement with filter production would both be solutions to the problems found with filter construction. Enhanced community education regarding both safe water handling and filter functionality and maintenance has the ability to greatly increase the overall efficiency of the filters.

The microbiology and survey data demonstrate the role of biosand filters as a sustainable solution to the biological water contamination issues faced by the community of Nkuv. They are consistently removing a substantial percentage of $E$. coli. While these filters are clearly not a perfect solution to Nkuv's water problems and some inconsistencies in their function remain, they nevertheless provide a significant improvement in water quality and in overall community health, and have become an integral part of the day-to-day life of community members.

\section{ACKNOWLEDGMENT}

The authors would like to acknowledge Peter Njodzeka and the LWDGC staff for their invaluable contributions to the success of this project. Financial support from the National Collegiate Inventors and Innovators Alliance (NCIIA) in the form of a Sustainable Vision grant is also gratefully acknowledged. Internal grants administered by Hope College that were funded by HHMI and the Crossroads Project were also critical to completing this work.

\section{REFERENCES}

[1] “Biosand Filter Manual: Design, Construction, Installation, Operation, and Maintenance”, pp. 18, A CAWST Training Manual (May 2010).

[2] “Biosand Filter Manual: Design, Construction, Installation, Operation, and Maintenance”, pp. 28, A CAWST Training Manual (May 2010). 
Appendix

May 2009 Nkuv Biosand Filter Assessment

\section{Filter Observations}

\begin{tabular}{|l|l|}
\hline Survey Date & \\
\hline Survey \# & \\
\hline Filter \# & \\
\hline Region & \\
\hline Construction Techs & \\
\hline Date of Construction & \\
\hline Date of last Start-up & \\
\hline
\end{tabular}

\begin{tabular}{|l|l|l|}
\hline Location & & \\
\hline Level Housing & & \\
\hline Filter Cleanliness & & \\
\hline Lid in Place & & \\
\hline Diffuser Plate & & \\
\hline Sand Level & & \\
\hline Leaks in Housing & & \\
\hline
\end{tabular}




\section{Household Practices}

Separate Storage Containers

Types of Containers (ex. Jerry cans, buckets)

Covered Containers

Clean Containers

Method of Transferring Water

All drinking water produced by filter

\section{User Perception}

Has the filter benefited the family?

Have there been any problems with the filter?

Has there been actions taken in reaction to the problems?

Does the family know how to clean the filter?

How often is the filter cleaned? 


\section{Microbiology Results}

\begin{tabular}{|l|l|}
\hline Flow-rate & \\
\hline Date & \\
\hline
\end{tabular}

\begin{tabular}{|r|l|l|l|l|}
\hline Test & Sample Type & $\mathrm{mL}$ & E-coli Coliforms & Total Coliforms \\
\hline 1 & & & & \\
\hline 2 & & & & \\
\hline 3 & & & & \\
\hline 4 & & & & \\
\hline 5 & & & & \\
\hline 7 & & & & \\
\hline 8 & & & & \\
\hline 9 & & & & \\
\hline 10 & & & & \\
\hline
\end{tabular}

\section{Date}

\begin{tabular}{|r|l|l|l|l|}
\hline Test & Sample Type & $\mathrm{mL}$ & E-coli Coliforms & Total Coliforms \\
\hline 1 & & & & \\
\hline 2 & & & & \\
\hline 3 & & & & \\
\hline 4 & & & & \\
\hline 5 & & & & \\
\hline 6 & & & & \\
\hline 7 & & & & \\
\hline 8 & & & & \\
\hline 9 & & & & \\
\hline 10 & & & & \\
\hline
\end{tabular}

